\title{
Extended Endoscopic Approach for Resection of Craniopharyngiomas
}

\author{
João Paulo Almeida ${ }^{1}$ Suganth Suppiah ${ }^{1} \quad$ Claire Karekezi $^{1} \quad$ Miguel Marigil-Sanchez $^{1}$ Jay S. Wong ${ }^{2}$ \\ Allan Vescan ${ }^{2}$ Fred Gentili ${ }^{1}$ Gelareh Zadeh ${ }^{1}$ \\ ${ }^{1}$ Division of Neurosurgery, Toronto Western Hospital, University of
Toronto, Toronto, Ontario, Canada
${ }^{2}$ Department of Otolaryngology/Head and Neck Surgery, Mount Sinai
Hospital, University of Toronto, Toronto, Ontario, Canada \\ Address for correspondence João Paulo Almeida, MD, Division of \\ Neurosurgery, Toronto Western Hospital, 4th Floor 399 Bathurst \\ Street, Toronto, ON M5T 2S8, Canada \\ (e-mail: jpaulocavalcante@yahoo.com.br).
}

J Neurol Surg B 2018;79(suppl S2):S201-S202.

\begin{abstract}
Keywords

- craniopharyngiomas

- tuberculum

- endoscopic

- extended

- endonasal

Objectives Extended endoscopic approaches are useful for resection of selected craniopharyngiomas. Midline, extraventricular, and predominantly cystic lesions are good candidates for endoscopic resection. In this video, we demonstrate the endoscopic endonasal resection of a large suprasellar craniopharyngioma and discuss the nuances of the surgical technique.

Design/Setting Surgical video of an extended endoscopic approach for resection of a suprasellar craniopharyngioma.

Results We report the case of a 56-year-old woman who presented with bitemporal hemianopsia and visual acuity deterioration secondary to a large suprasellar solid-cystic lesion. The patient underwent an extended endoscopic transtuberculum approach for resection of the lesion, which was diagnosed as a papillary craniopharyngioma. This video discusses the anatomy and surgical technique applied for endoscopic resection of such lesions. Conclusion Endoscopic endonasal surgery is a useful technique for management of craniopharyngiomas. It is associated with good clinical outcomes in selected cases. Complications, such as postoperative CSF leak, may occur and should be carefully managed. The link to the video can be found at: https://youtu.be/EneOCiQE7yo.
\end{abstract}

Conflict of Interest

None.

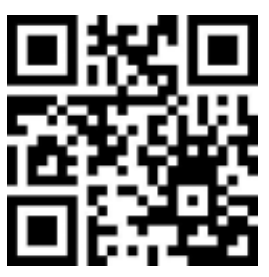

www.thieme.com/skullbasevideos

www.thieme.com/jnlsbvideos

received

October 12, 2017

accepted

December 12, 2017

published online

January 16, 2018
DOI https://doi.org/

10.1055/s-0037-1620244.

ISSN 2193-6331.
๑) 2018 Georg Thieme Verlag KG
Stuttgart · New York

License terms

() (i) $\ominus$ (\$) 


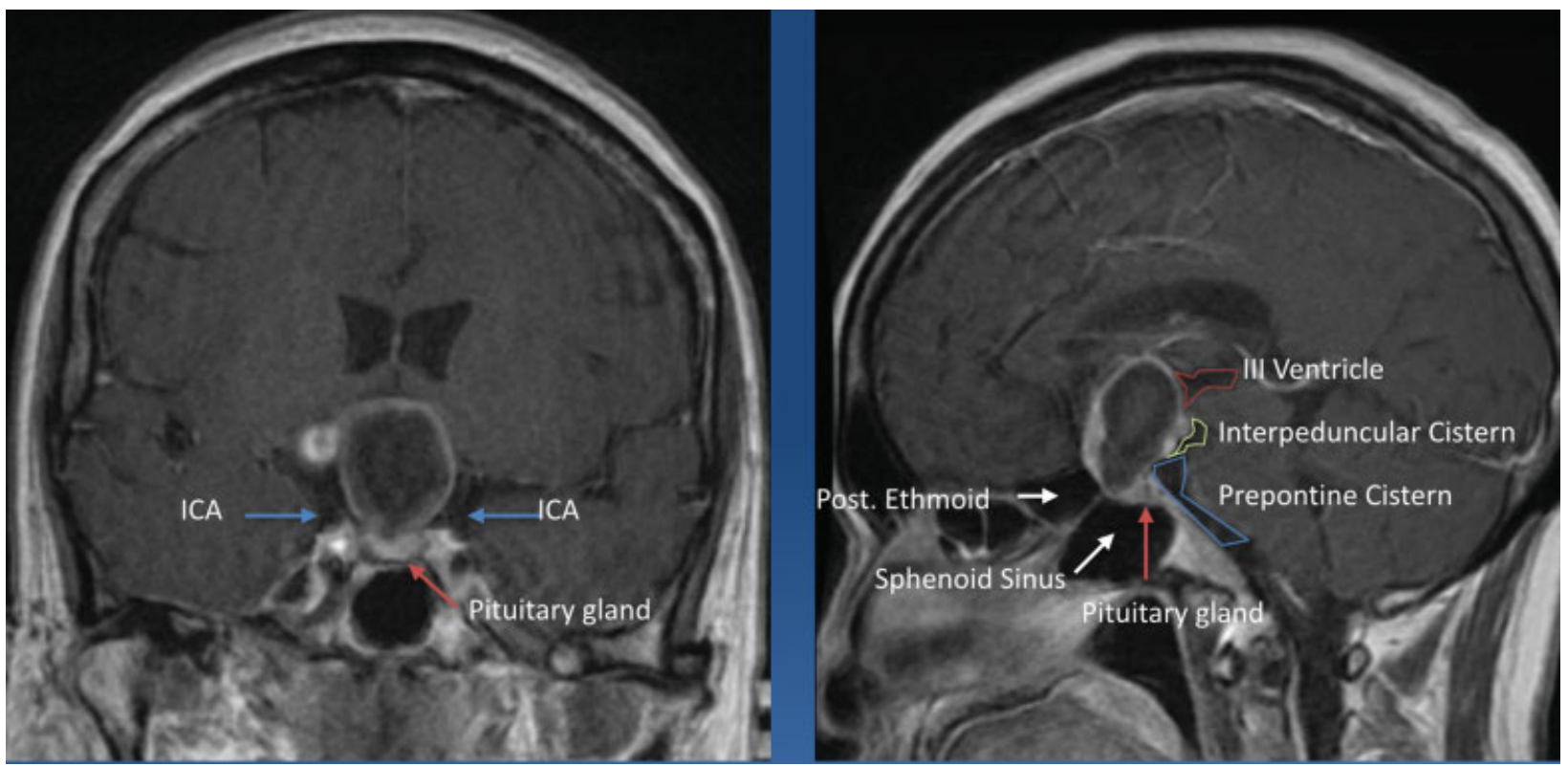

Fig. 1 Preoperative MRI scan demonstrating a suprasellar tumor, suggestive of craniopharyngioma. The coronal T1 contrast-enhanced scan (left) shows the lesion, located medial to the clinoid and supraclinoid internal carotid arteries and superior to the pituitary gland (as demonstrated by the arrows), compressing the optic chiasm. The sagittal imaging (right) demonstrates the relationship of the lesion with the floor of the III ventricle and basal cisterns (right). ICA, internal carotid artery; MRI, magnetic resonance imaging.

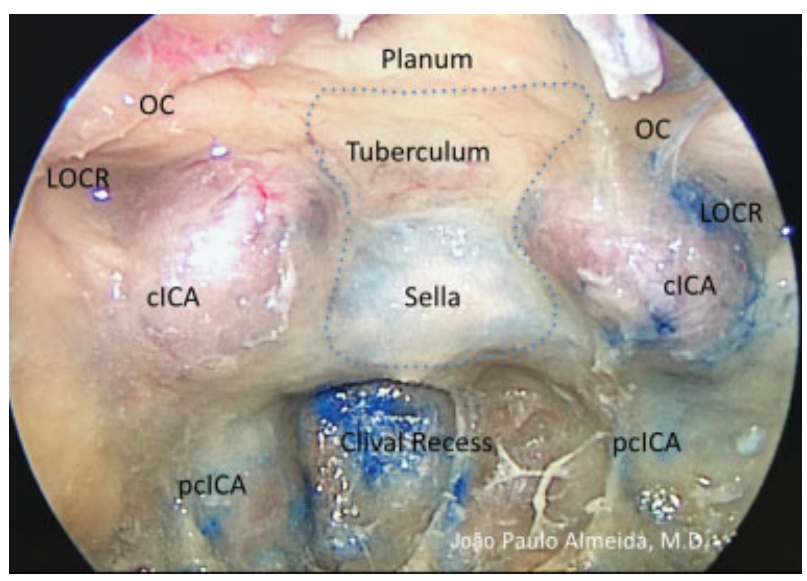

Fig. 2 Transtuberculum approach: surgical anatomy. The anatomical direction demonstrates the anatomical structures related to the transtuberculum approach. CICA, clinoid segment of the internal carotid artery; LOCR, lateral optic carotid recess; PcICA, paraclival segment of the internal carotid artery; OC, optic canal. Dashed line demonstrates the area of bone opening for the transtuberculum approach (copyright $\odot$ Joao Paulo Almeida, MD).

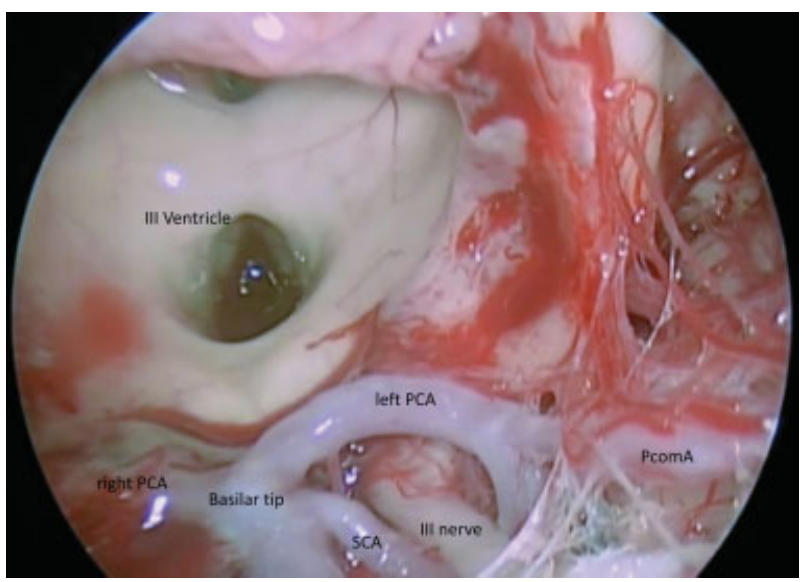

Fig. 3 Exposure of the III ventricle and interpeduncular cistern after tumor resection. The basilar tip, PCA and SCA, III nerve, and PcomA are visible. PCA, posterior cerebral; PcomA, posterior communicating artery; SCA, superior cerebellar. 